\title{
Simulation of processes of electric power consumption for traction in conditions of changing the traffic schedule of freight trains at the electrified sections
}

\author{
Vladislav Nezevak ${ }^{1, *}$, Elena Sidorova ${ }^{1}$, and Yury Demin $^{2}$ \\ ${ }^{1}$ Omsk State Transport University, 644046, Marx av., 35, Omsk, Russia \\ ${ }^{2}$ Siberian State University of Water Transport, 630099, Schetinkina st., Novosibirsk, Russia
}

\begin{abstract}
The paper is devoted to the solution of the problem of increasing the energy efficiency of the transportation process on the electrified sections of the railways. The task is considered in the aspect of energy efficiency when comparing forecasted traffic schedules with each other and assessing the effectiveness of implementing the forecasted and executed schedule of train traffic at the section. The basis for the calculations is a simulation modeling of the interaction between the electric rolling stock and the traction power supply system at the sections with different track profiles. Simulation modeling was carried out for the conditions of changing the traffic schedule of freight trains and maintaining the amount of traffic and the amount of work unchanged. The results of the change in the amount of electric power for traction and the level of unbalance of energy for existing sections of constant and alternating current are used as the basis for construction of approximating models, in the function of which regression and neural network models are used. Comparison of the results of approximation of the considered models for the estimation of changes in amount of electric power for traction and unbalance is made. Models with the best results of approximation to simulation results are determined.
\end{abstract}

\section{Introduction}

Increasing the energy efficiency of the transportation process is one of the priority tasks facing the holding company "RZD". One of the directions for increasing energy efficiency is the construction of forecasted train traffic schedules at the electrified sections of railways by taking into account the efficiency of using fuel and energy resources.

To achieve the level of energy efficiency in the strategic planning of the holding's development, a number of target benchmarks have been set. Thus, with the current value of the specific consumption of electrical energy in the freight traffic at the level of $160.7 \mathrm{kWh} / 10$ thousand tonnes $\mathrm{km}$ net in 2015 , the target benchmark for 2030 is set at $151.9 \mathrm{kWh} / 10$ thousand tonnes $\mathrm{km}$ net.

\footnotetext{
* Corresponding author: NezevakWL@mail.ru
} 
The solution of the problem of increasing the energy efficiency of the transportation process in the aspect of construction of energy-saving traffic schedules is aimed at reducing power consumption when operating a train from the departure station to the destination station and reducing the number of stops for freight trains [Ошибка! Источник ссылки не найден., Ошибка! Источник ссылки не найден.]. At the same time, a great potential for increasing the energy efficiency of transportations is in the field of solving problems related to the regulation of the parameters of the schedule of freight trains on the section while maintaining the amount of traffic [Ошибка! Источник ссылки не найден. Ошибка! Источник ссылки не найден.]. This direction of work is associated with a reduction in the level of unbalance of electrical energy in the traction power supply system and an improvement in the conditions for the use of the electric rolling stock of regenerative braking. At the present time, the task of comparison of different forecasted traffic schedules among themselves is not solved, as well as the comparison of the executed traffic schedule with the forecasted one based on the energy efficiency criterion. Based on the above, taking into account the active development of the issues of the above problems abroad [Ошибка! Источник ссылки не найден. - Ошибка! Источник ссылки не найден.], the solution of this problem seems relevant and of great practical importance.

\section{Methods of calculation}

The effect of the train traffic schedule on the power consumption for traction on traction substations is determined by two main factors - the schedule of electric load of traction substations and the conditions for the application of regenerative braking of an electric rolling stock. In the first case, the traffic schedule determines the schedule of the electric load of substations, which in turn determines the level of technical losses of electric energy in the traction power supply system; in the second case, the conditions of application of regenerative braking influence the amount of power consumption by traction substations [Ошибка! Источник ссылки не найден. - Ошибка! Источник ссылки не найден.]. Since the level of energy efficiency and the specific power consumption for traction is determined from the data of measuring instruments of traction substations, it is necessary to consider the change in the electric power consumption of the electric rolling stock and the unbalance in the traction power system together.

In general, the amount of electrical energy for traction for comparison purposes is determined by comparative periods - the base and the reporting periods. As the indicated periods, the month, quarter, half year, and year are used. To assess the energy efficiency of the transportation process, it is necessary to identify the energy component that depends on the train traffic schedule. In this case, there are two types of traffic - passenger and freight. For sections of the railways of direct current, the amount of electric power for traction in freight and passenger traffic during the period under consideration is determined by the expression:

$$
W_{T S S(\text { fre }+ \text { pas })}=W_{\text {section }}-\frac{W_{E R S \text { serv }}+W_{E R S \text { shun }}+W_{T S S \text { nontr }}}{100-\delta_{\text {section }}} \cdot 100
$$

where $W_{\text {section }}$ - the amount of electric power from the inputs of converter (for direct current) or step-down (for alternating current) transformers of traction substations (TSS) supplying the contact network within the boundaries of the section, thousand $\mathrm{kW} \mathrm{h}$;

$W_{\text {ERS serv }}$ - the amount of electric power without taking into account the unbalance in the service traffic at the section under consideration, thousand $\mathrm{kW} \mathrm{h}$;

$W_{\text {ERS shun }}$ - the amount of electric power without taking into account the unbalance for shunting work at the section under consideration, thousand $\mathrm{kW} \mathrm{h}$; 
$W_{\text {TSS nontr }}$ - the amount of electric power without taking into account the unbalance for nontraction needs from the connections of the contact network of traction substations located within the boundaries of the section under consideration, thousand $\mathrm{kW} \mathrm{h}$;

$\delta_{\text {section }}$ - relative value of unbalance at the considered section of direct current for the base period, $\%$ :

$$
\delta_{\text {section }}=\left(1-\frac{W_{\text {ERS trac }}+W_{\text {TSS nontr }}}{W_{\text {section }}}\right) \cdot 100
$$

$W_{\text {ERS trac }}$ - the amount of electric power consumption for all types of traffic and for shunting work within the boundaries of the section, thousand $\mathrm{kW} \mathrm{h}$.

For sections of railways of alternating current, the volume of electric power for traction in the period under consideration is determined by the expression:

$$
\begin{gathered}
W_{T S S(\text { fre }+ \text { pas })}=W_{\text {section }}-W_{D P R}-W_{T A N}- \\
\frac{W_{E R S \text { serv }}+W_{E R S \text { shun }}+W_{T S S \text { nontr }}}{100-\delta_{\text {section }}} \cdot 100,
\end{gathered}
$$

where $W_{D P R}$ - the amount of electric power consumption for longitudinal power supply connections (DPR) of traction substations located within the boundaries of the section under consideration, thousand $\mathrm{kW}$ h;

$W_{T A N}$ - the amount of electric power consumption for connection of transformers of auxiliary needs (TAN) of traction substations (including the connections of the main distribution frame (MDF) and signaling, centralization, and blocking (SCB) in the presence of separate accounting) located within the boundaries of the section under consideration, thousand $\mathrm{kW} \mathrm{h}$.

$\delta_{\text {section }}$ - relative value of unbalance at the considered section of alternating current for the base period, $\%$ :

$$
\delta_{\text {section }}=\left(1-\frac{W_{E R S \text { trac }}+W_{T S S \text { nontr }}+W_{D P R}+W_{T A N}}{W_{\text {section }}}\right) \cdot 100 .
$$

Based on the procedure for determining the amount of power consumption for traction, it is possible to determine the main approaches to simulating the interaction between the electric rolling stock and the traction power supply system. When considering the effect of the train traffic schedule on the amount of power consumption from the expressions (1) - (4), it is permissible to exclude values which are not directly related to the traction of trains. These values include the following: $W_{\text {ERS shun, }} W_{\text {TSS nontr, }}, W_{D P R}, W_{T A N}$. The specified assumption allows keeping the existing order of calculations, simplifies them, and creates conditions for obtaining dependencies of the effect of the train traffic schedule on the amount of power consumption for traction. A number of statistical indicators describing the parameters of the traffic schedule is not informative and cannot be used for the problem under consideration [Ошибка! Источник ссылки не найден.]. Estimation of the effect of the freight train traffic schedule on power consumption for traction is proposed to be performed by taking into account the following main parameters of the schedule: interval between trains in the bunch (set); interval between bunches (sets) of trains or in the passage outside bunches (sets); number of bunches (sets) and trains in bunches (sets) of the schedule; number of stops of freight trains; number of solid train paths of the freight train traffic schedule in the traffic schedule under consideration.

To formalize the description of the train traffic schedule for the base and reporting periods, as well as the period in which the forecasted traffic schedule is planned (hereinafter referred to as the settlement period), the following calculation parameters are proposed. 
The relative time of passage of freight trains in the bunches (sets - depending on the use of automatic or semi-automatic blocking on the section) takes into account the intervals between trains and is determined for the daily schedule in relative units (r.u.) according to the formula:

$$
\alpha=\frac{\sum_{i} \tau_{\text {train } i}}{1440 \cdot N_{\text {main }}},
$$

where $\tau_{\text {train } i}-\mathrm{i}$-th interval between trains in the bunch (set) of freight trains, min.;

$\mathrm{N}_{\text {main }}$ - the number of main tracks at the designed operating domain, units;

1440 - conversion factor to convert days to minutes.

The organization of the train traffic with automatic blocking and semi-automatic blocking makes it necessary to take into account the changes in the intervals between trains in bunches and sets in simulation modeling in a wide range of 8 to 20 minutes. The specified range covers the intervals between trains which are most common in practice in various conditions of the infrastructure and the length of distances between stations.

The minimum number of freight trains in the bunch (set) for calculating $\alpha$ is assumed to be three. In this case, the interval between freight trains in the bunch (set) should be less than 20 minutes. Otherwise it is assumed that the trains passing with an interval of more than 20 minutes pass outside the bunch (set) and the intervals between trains are not taken into account during calculation of $\alpha$. If all intervals between trains in the schedule exceed 20 minutes, the parameter $\alpha$ is assumed to be zero. The relative time (5) is determined by the time of passing the stations limiting operating domain separately, and then averaged by the considered periods.

The average value of the number of freight trains in the bunches (sets) for the daily schedule is determined by the formula:

$$
n_{\text {freight av }}=\frac{\sum_{i} n_{\text {freight } i}}{N_{\text {bun freight }}}
$$

where $n_{\text {freight. i }}$ - the number of freight trains in the i-th bunch (set);

$N_{\text {bun freight }}-$ the number of bunches (sets) of freight trains in the train traffic schedule.

The specific weight of stops of freight trains in the traffic schedule is determined by the formula:

$$
\beta=\frac{n_{\text {freight stop }}}{n_{\text {sched }} \cdot N_{\text {main }}},
$$

where $n_{\text {freight stop }}-$ the number of train paths of freight trains containing stops due to the linking of schedules by the control sections or by the joints of railways;

$n_{\text {sched }}$ - the number of pairs of freight trains in the traffic schedule.

The specific weight of solid train paths in the schedule for freight trains is determined by the formula:

$$
\gamma=\frac{n_{e}}{n_{\text {sched }} \cdot N_{\text {main }}},
$$

where $n_{e}-$ the number of solid train paths in the schedule for freight trains.

The coefficient of intensity of the passing freight trains in the bunches (sets) is determined by the formula:

$$
k_{i}=\frac{8}{\tau_{a v}}
$$


where $\tau_{a v}$ - average interval between trains in the bunches (sets).

The coefficient of intensity of the passing freight trains outside the bunches (sets) is determined by the formula:

$$
k_{i \text { bun }}=\frac{20}{\tau_{\text {av. bun }}}
$$

where $\tau_{a v \text {.bun }}$ - average interval between trains outside the bunches (sets).

The proposed method of calculation is as follows. At the first stage of calculations, the amount of electric power for traction and the level of unbalance in terms of expressions (1) - (4) is determined. At the second stage, the parameters of the train traffic schedule are determined by the expressions (5) - (10). On the basis of simulation modeling, these calculations are repeated in order to obtain the dependences of the change in the volume of electric power for traction and unbalance. The obtained dependencies are subsequently used to compare forecasted traffic schedules among themselves or a comparison of forecasted and executed schedules. The application of these dependencies is based on the use of calculations in relative units. To this end, the obtained dependences of the change in the amount of power consumption and unbalance of electric power are reduced to the base values, which are the minimum values obtained when performing the corresponding calculations. This transition to relative units allows further use of the simulation results for any sections, since it relies on calculation of the values in the base period in absolute terms. The simulation of the interaction between the electric rolling stock and the traction power supply system makes it possible to obtain the averaged dependences of the changes in the amount of electric power consumption for traction and unbalance of electric power from the parameters of the train schedule for a number of sections of railways with the corresponding types of current and the types of track profiles.

\section{Results of calculations}

The simulation modeling is based on traction calculations performed for sections with different type of track profile. For each of the four types of track profile, three existing sections of the railways have been selected with the aim of subsequently averaging the results. The average length of the sections is $200 \mathrm{~km}$. The results of determining the specific consumption for the three variants of traction calculations are shown in Fig. 1. The first option is traction calculation for a freight train when passing through a section without stops, the second one - with one stop, the third one - without stopping with the optimization of coasting (energy saving). Traction calculations are performed in groups of three DC and AC sections for each type of track profile.

On the basis of the traction calculations received, a number of traffic schedules are subsequently generated by changing the timetable for freight train traffic with unchanged amount of traffic and the amount of work done. The difference between timetables of schedules consists in alternation of intervals between trains with different values, different number of bunches (for sections with automatic blocking) or sets (for sections with semiautomatic blocking), stops and energy-optimal train paths in freight traffic. 


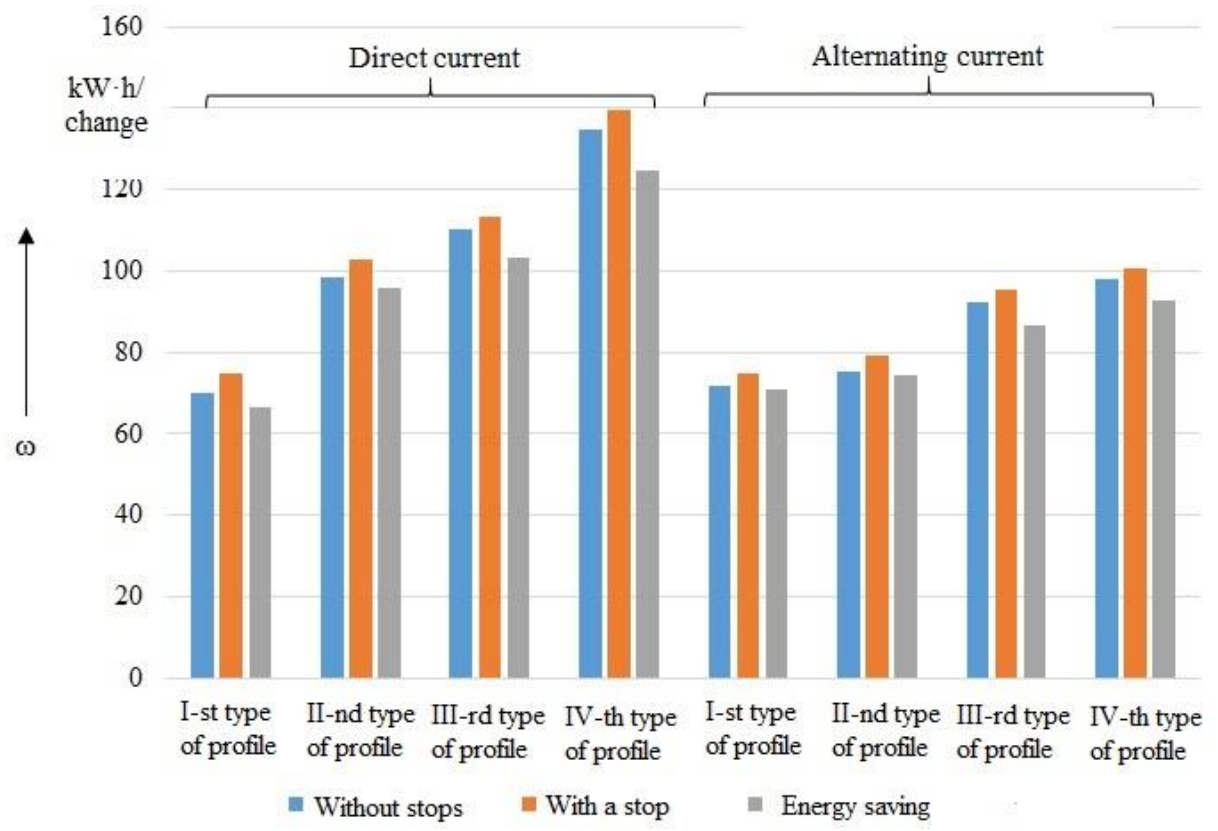

Fig. 1. Specific power consumption in freight traffic for sections with different type of profile.

A set of variants for construction of train traffic schedules is illustrated by the example of the three variants shown in Fig. 2, which shows a fragment of the schedule with the same intervals between trains (a) and fragments with a different number of bunches and trains in them ( $b$ and $c)$.

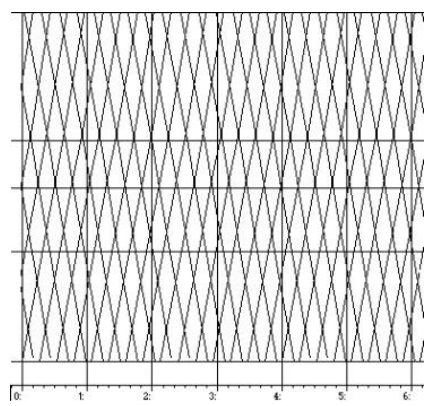

$\mathrm{a}$

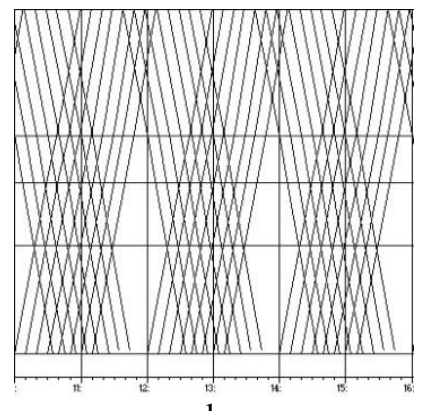

b

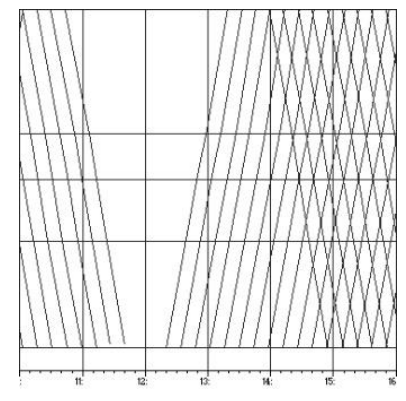

$\mathrm{c}$

Fig. 2. Fragments of different variants for implementing the schedule.

A set of parameters (expressions (5) - (10)) and values of the amount of electric power and unbalance correspond to the generated set of variants of traffic schedules. The obtained simulation data are intended to form further models for describing the processes of power consumption for traction and unbalance of electric power when the timetable for freight train traffic changes.

\section{Application of the results}

Regression models for estimating power consumption in various areas are used quite widely. Along with them, the apparatus of neural networks has proved itself to be very useful, which, in some cases, makes it possible to achieve better results in describing the processes of power 
consumption [Ошибка! Источник ссылки не найден. - Ошибка! Источник ссылки не найден.]. In order to use the results of simulation modeling, it is proposed to use a nonlinear regression model as one of the possible solutions. The received model allows carrying out an estimation of change of the amount of power consumption and unbalance at the section under consideration.

The estimated amount of electric power for traction in freight and passenger traffic in total without taking into account the unbalance for the period under consideration for each type of current and the type of track profile is determined in relative term using the following expression, r.u.:

$$
\begin{aligned}
& W_{\text {ERS (fre }+ \text { pas) rel }}=a_{11} \cdot k_{i}+a_{12} \cdot k_{i \text { bun }}+a_{13} \cdot \frac{1}{1+e^{-\left(\alpha^{b a s s}-0.5\right)}}+a_{14} \cdot n_{a v}+a_{15} \cdot \beta+ \\
& +a_{16} \cdot \gamma+a_{21} \cdot k_{i}^{2}+a_{22} \cdot k_{i \text { bun }}^{2}+a_{23} \cdot \frac{1}{1+e^{-2 \cdot(-\alpha+0.5)}}+a_{24} \cdot n_{a v}^{2}+a_{25} \cdot \beta^{2}+a_{26} \cdot \gamma^{2}+b,
\end{aligned}
$$

where $a_{11 \ldots} a_{26}$ - empirical coefficients; $b$ - free member of model.

The calculated value of unbalance at the section under consideration for the base and design periods for the corresponding type of current and the type of the track profile (in relative units, r.u.) is defined similarly to (11). The coefficient of determination for regression models of the form (11) describing the change in the amount of power consumption and unbalance exceeds 0.9 , and the average absolute error does not exceed $3.0 \%$. At the same time, the use of regression models does not allow achieving such results as neural networks do. Thus, the use of models of multilayer perceptrons allows reducing the level of the mean absolute error to 1\% [Ошибка! Источник ссылки не найден.].

For the purpose of assessing the effect of the train traffic schedule, it is proposed to use the amount of electric power consumption in relative term (11), calculated for traction in freight and passenger traffic in total without taking into account the unbalance per relative unit of its consumption for the considered section of the design operating domain in the base period, thousand $\mathrm{kW} \mathrm{h/r.u.:}$

$$
b_{E R S(\text { fre }+ \text { pas }) r e l}=\frac{W_{E R S(\text { fre }+ \text { pas })}}{W_{E R S(\text { fre }+ \text { pas }) r e l}},
$$

where $W_{\text {ERS(fre+pas), }} W_{\text {ERS(fre+pas)rel }}$ - the amounts of electric power for traction in freight and passenger traffic in total without taking into account unbalance at the section under consideration in absolute and relative terms, thousand $\mathrm{kW} h$ and r.u., respectively.

The introduction of this value allows further calculation in absolute units for estimation of the effect in absolute term.

The value of unbalance in relative terms in the freight and passenger traffic (with the exception of shunting work and service traffic) in the period under consideration taking into account the share of electric power consumption is determined by the expression, thousand $\mathrm{kW}$ h/r.u.:

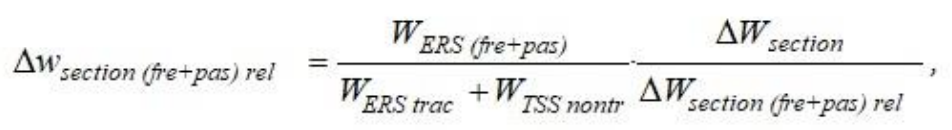

where $\Delta W_{\text {section(fre+pas)rel }}$ - the amount of unbalance pertaining to freight and passenger traffic at the section under consideration in relative units, r.u.;

$\Delta W_{\text {section }}$ - the absolute value of unbalance at the section under consideration of the design operating domain for the base period, thousand $\mathrm{kW} \mathrm{h}$ :

a) for the considered section of direct current - 


$$
\Delta W_{\text {section }}=W_{\text {section }}-\left(W_{E R S \text { trac }}+W_{\text {TSS nontr }}\right) \text {; }
$$

b) for the considered section of alternating current -

$$
\Delta W_{\text {section }}=W_{\text {section }}-\left(W_{\text {ERS trac }}+W_{\text {TSS nontr }}+W_{D P R}+W_{\text {TAN }}\right.
$$

To compare the traffic schedules by the criterion of energy efficiency, it is suggested to use in calculation the following design values.

Design value of amount of electric power for traction in freight and passenger traffic in total without taking into account unbalance in the design period for the $i$-th variant of the schedule, thousand $\mathrm{kW} \mathrm{h}$ :

$$
W_{E R S(f r e+p a s) i}=b_{E R S \text { (fre }+ \text { pas) rel }} \cdot W_{E R S \text { (fre }+ \text { pas) rel } i} \text {. }
$$

Design absolute value of unbalance related to freight and passenger traffic in the design period for the $i$-th variant of the schedule, thousand $\mathrm{kW} \mathrm{h}$ :

$$
\Delta W_{\text {section (fre }+ \text { pas) } i}=\Delta w_{\text {section (fre }+ \text { pas) rel }}-\Delta W_{\text {section (fre }+ \text { pas) rel } i} .
$$

A comparison of the power consumption for the $i$-th variant of the schedule with another or basic variant allows determining the traffic schedule with the greatest energy efficiency. The effect is determined in absolute terms by the following expression, thousand $\mathrm{kW} \mathrm{h}$ :

$$
\Delta W_{\text {TSS (fre }+ \text { pas }) i}=W_{T S S \text { (fre }+p a s)}-\left(W_{E R S(f r e+p a s) i}+\Delta W_{\text {section (fre }+p a s) i}\right),
$$

The relative value of a change in the volume of electric power taking into account the unbalance in the design period relative to the base for the $i$-th variant of the schedule is determined by the expression, $\%$ :

$$
\delta_{\text {TSS fre PTS }}=\frac{\Delta W_{\text {TSS (fre }+ \text { pas }) i}}{W_{\text {TSS (fre }+ \text { pas })}} \cdot 100 .
$$

The results of comparison of different variants of traffic schedules in the simulation modeling of power consumption processes for traction and the level of unbalance of electric power at the sections of DC and $\mathrm{AC}$ with different types of track profile show the influence on them of the parameters of the train schedule. In the conditions of the organization of freight traffic, the influence of the parameters of the schedule can lead to a change in the amount of power consumption by $3-10 \%$ for the sections of direct current and by $3-4 \%$ for the sections of alternating current, while changes in unbalance for the sections of direct current are observed in the range $1-1.5 \%$, for the sections of alternating current in the range $-1.3 \%$. This potential emphasizes the need to take into account the effect of the freight train schedule on the energy efficiency of the transportation process.

\section{Conclusions}

Based on the report data on power consumption and the parameters of the traffic schedule at the real section, the proposed calculation procedure based on simulation modeling and calculation in relative units allows estimation of the energy efficiency of the forecasted and executed traffic schedules and estimation of efficiency in absolute terms. The obtained results 
of the estimation of the effect of the parameters of the forecasted train traffic schedules on the amount of electric power for traction taking into account the unbalance make it possible to choose the best of the permissible variants. The above calculation procedure is oriented to the use of regression models and neural networks and is designed to estimate the effect of the traffic schedule parameters on the amount of power consumption and unbalance of electric power at the railway sections or operating domains. The proposed calculation methodology is the basis for the estimation of the forecasted train schedules on the basis of the energy efficiency criterion.

\section{References}

1. L.A. Muginshtein, A.E. Ilyutovich, I.A. Yabko, Bulletin of the Research Institute of Railway Transport 6, 3-13 (2013)

2. V.Yu. Kiryakin, A.V. Novgorodtseva, Bulletin of the Joint Scientific Council of JSC "RZD" 1, 16-20 (2014)

3. V.L. Nezevak, Transport of the Urals 4(55), 65-70 (2017)

4. V.L. Nezevak, Izvestiya Transsiba 2(30), 87-99 (2017)

5. V.T. Cheremisin, V.L. Nezevak, S.S. Sarkenov, Modern technologies. System analysis. Modeling 3(55), 135-144 (2017)

6. G.M. Scheepmaker, R.M.P. Goverde, L.G. Kroon, European Journal of Operational Research (2016) doi: 10.1016/j.ejor.2016.09.044

7. T. Montrone, P. Pellegrini, P. Nobili, Springer Proceedings in Mathematics and Statistics 217, 485-493 (2017)

8. Z. Tian, S. Hillmansen, C. Roberts, S. Su, T. Xin, 17th IEEE International Conference on Intelligent Transportation Systems, ITSC 6958067, 2354-2359 (2014)

9. P. Lukaszewicz, Advances in Transport 15, 901-909 (2004)

10. K. Warayut, K. Takafumi, Energy Procedia 138, 795-800 (2017)

11. V.L. Nezevak, V.T. Cheremisin, A.P. Shatokhin, Bulletin of the Tomsk Polytechnic University, Georesources Engineering 326-10, 54 - 64 (2017)

12. V.L. Nezevak, A.P. Shatokhin, Transport world 16-2 (75), 84-94 (2018)

13. V.L. Nezevak, Vestnik transporta Povolzhya 6(66), 34-44 (2017)

14. V.T. Cheremisin, V.L. Nezevak, A.P. Shatokhin, Scientific monograph (Omsk State Transport University, Omsk, 2018)

15. V.L. Nezevak, Bulletin of the Rostov State University of Railway Transport 4(68), 159170 (2017)

16. N. Fumo, M.A. Rafe Biswas, Renewable and Sustainable Energy Reviews 47, 332-343 (2015)

17. C.P. Barros, P. Wanke, S. Dumbo, J. P. Manso, Renewable and Sustainable Energy Reviews 78, 588-596 (2017)

18. N.V. Raevsky, V.G. Litvintsev, Modern technologies. System analysis. Modeling 4, 192-196 (2010)

19. V.T. Cheremisin, A.A. Komyakov, V.I. Ivanchenko, Omsk Scientific Bulletin 6(150), 77-81 (2016)

20. N.V. Raevsky, V.G. Litvintsev, Scientific problems of transport in Siberia and the Far East 2, 298-301 (2010) 